\title{
Amorphization and Solid-Phase Epitaxial Growth of C-Cluster Ion-Implanted Si
}

\author{
N.G. RUDAWSKI, ${ }^{1,2}$ L.R. WHIDDEN, ${ }^{1}$ V. CRACIUN, ${ }^{1}$ and K.S. JONES ${ }^{1}$ \\ 1.-Department of Materials Science and Engineering, University of Florida, Gainesville, \\ FL 32611-6400, USA. 2.-e-mail: ngr@ufl.edu
}

Amorphization and solid-phase epitaxial growth were studied in C-cluster ion-implanted $\mathrm{Si} . \mathrm{C}_{7} \mathrm{H}_{7}$ ions were implanted at a C-equivalent energy of $10 \mathrm{keV}$ to $\mathrm{C}$ doses of $0.1 \times 10^{15} \mathrm{~cm}^{-2}$ to $8.0 \times 10^{15} \mathrm{~cm}^{-2}$ into (001) Si wafers. Transmission electron microscopy revealed a $\mathrm{C}$ amorphizing dose of $\sim 5.0 \times$ $10^{14} \mathrm{~cm}^{-2}$. Annealing of amorphized specimens to effect solid-phase epitaxial growth resulted in defect-free growth for $\mathrm{C}$ doses of $0.5 \times 10^{15} \mathrm{~cm}^{-2}$ to $1.0 \times 10^{15} \mathrm{~cm}^{-2}$. At higher doses, growth was defective and eventually polycrystalline due to induced in-plane tensile stress from substitutional $\mathrm{C}$ incorporation.

Key words: Cluster-ion implantation, $\mathrm{Si}$, amorphization, strain, stress, solid-phase epitaxial growth

\section{INTRODUCTION}

The International Technology Roadmap for Semiconductors specifies the need for ultrashallow junctions (USJs) with enhanced performance properties. ${ }^{1}$ However, it is challenging to form USJs via ion implantation of single ions due to the difficulty in generating very low implant energies with commercially available implanters and the extensive primary damage formed after single-ion implantation. ${ }^{2,3}$ The use of cluster-ion implantation provides a possible solution to these challenges. ${ }^{4,5}$ In particular, use of cluster ions allows implanter operation at more conventional accelerating voltages. If the implant energy of a single ion with mass $M_{\text {ion }}$ is $E_{\text {equiv }}$, then the corresponding implantation energy required for cluster-ion implantation is given by $E_{\text {cluster }}=E_{\text {equiv }}\left(M_{\text {cluster }} / M_{\text {ion }}\right){ }^{6-8}$ Thus, since typically $M_{\text {cluster }} / M_{\text {ion }} \gg 1$, higher implant energies may be used than for the single-ion case. Additionally, cluster-ion implantation produces denser, more compact damage regions compared with single-ion implantation, with fewer transmitted ions and recoils and thus fewer generated excess

(Received February 23, 2009; accepted June 4, 2009; published online June 25, 2009) point defects after formation of an amorphous ( $\alpha$ ) layer. ${ }^{9}$ Cluster-ion implantation also has the potential for higher device fabrication throughput since the equivalent dose of single ions ( $\left.Q_{\text {equiv }}\right)$ is related to the dose of cluster ions $\left(Q_{\text {cluster }}\right)$ by $Q_{\text {cluster }}=Q_{\text {equiv }} / N_{\text {cluster, }}$, where $N_{\text {cluster }}$ is the number of atoms per cluster. ${ }^{10}$ In particular, the use of C-cluster ion implantation is of technological interest due the ability of $\mathrm{C}$ to slow the diffusion of certain dopants ${ }^{11-13}$ during post-implantation annealing and enhance charge carrier mobility due to induced strain resulting from substitutional C incorporation during solid-phase epitaxial growth (SPEG). ${ }^{14-16}$ Thus, the goal of this study is to observe the evolution of damage in C-cluster ionimplanted $\mathrm{Si}$ and the subsequent SPEG process.

\section{EXPERIMENTAL PROCEDURES}

In this study, $\mathrm{C}_{7} \mathrm{H}_{7}$ clusters were ion-implanted at room temperature at $E_{\text {equiv }}=10 \mathrm{keV}$ to $Q_{\text {equiv }}=$ $0.1 \times 10^{15} \mathrm{~cm}^{-2}$ to $8.0 \times 10^{15} \mathrm{~cm}^{-2}$ into $(001) \mathrm{Si}$ wafers. Subsequently, the samples were annealed in $\mathrm{N}_{2}$ ambient at $800^{\circ} \mathrm{C}$ for $0.5 \mathrm{~h}$. On-axis highresolution cross-sectional transmission electron microscopy (HR-XTEM) and weak-beam dark-field plan-view and cross-sectional TEM (WBDF-PTEM and WBDF-XTEM) imaging were used to study the 

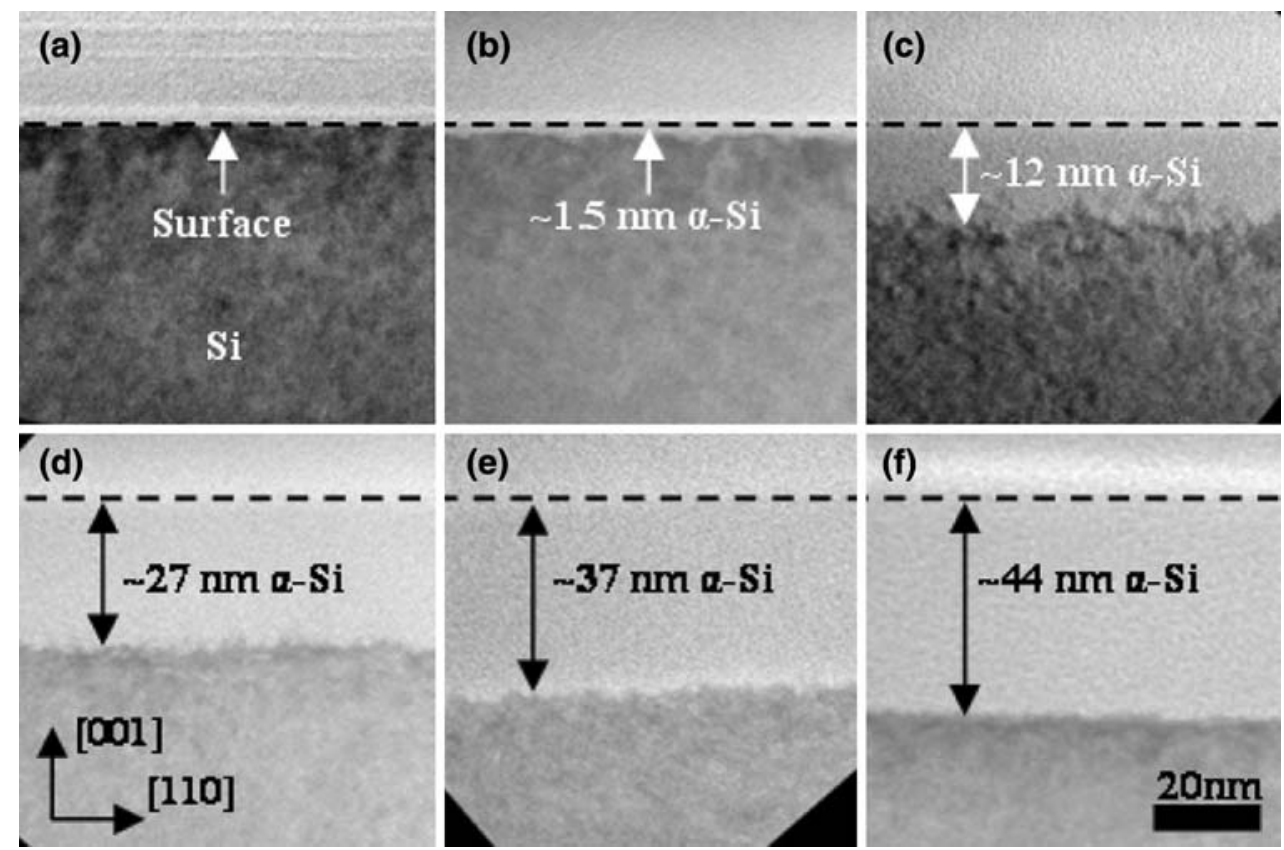

Fig. 1. HR-XTEM images of specimens implanted with $\mathrm{C}_{7} \mathrm{H}_{7}$ ions at a $\mathrm{C}$-equivalent energy of $10 \mathrm{keV}$ with $\mathrm{C}$ doses of (a) $3.0 \times 10^{14} \mathrm{~cm}^{-2}$, (b) $5.0 \times 10^{14} \mathrm{~cm}^{-2}$, (c) $1.0 \times 10^{15} \mathrm{~cm}^{-2}$, (d) $2.0 \times 10^{15} \mathrm{~cm}^{-2}$, (e) $4.0 \times 10^{15} \mathrm{~cm}^{-2}$, and (f) $8.0 \times 10^{15} \mathrm{~cm}^{-2}$.

evolution of damage. Selected-area electron diffraction (SAED) analysis was performed on annealed samples to evaluate the crystallographic nature of the damage.

\section{RESULTS AND DISCUSSION}

Figure 1a-f presents HR-XTEM images of the as-implanted specimens. In the cases of $Q_{\text {equiv }}=$ $1.0 \times 10^{14} \mathrm{~cm}^{-2}$ to $3.0 \times 10^{14} \mathrm{~cm}^{-2}$, shown in Fig. 1a, an $\alpha$-Si layer was not created. However, for $Q_{\text {equiv }}=5.0 \times 10^{14} \mathrm{~cm}^{-2}$, as shown in Fig. $1 \mathrm{~b}$, a $\sim 1.5$-nm-thick $\alpha$-Si layer was evident at the sample surface. The thickness of the $\alpha$-Si layer increases with $Q_{\text {equiv }}$ and reaches a value of $\sim 44 \mathrm{~nm}$ for $Q_{\text {equiv }}=8.0 \times 10^{15} \mathrm{~cm}^{-2}$, as shown in Fig. $1 \mathrm{c}-\mathrm{f}$. Thus, it appears that the $\mathrm{C}_{7} \mathrm{H}_{7}$ amorphization threshold is reached for $Q_{\text {equiv }} \approx 5.0 \times 10^{14} \mathrm{~cm}^{-2}$. There is little data available on $\mathrm{Si}$ amorphization from ion-implanted C. However, B, with a similar mass to $\mathrm{C}$, has been shown to induce surface amorphization for doses $\geq 1.0 \times 10^{16} \mathrm{~cm}^{-2}$, which is nearly 20 times the $Q_{\text {equiv }}$ value of $5.0 \times 10^{14} \mathrm{~cm}^{-2}$ reported here. ${ }^{17}$ Presumably, this is due to the denser damage cascades resulting from cluster implantation as opposed to single-ion implantation. ${ }^{9}$ However, it is interesting that the evolution of the $\alpha$-Si layer is very similar to that of single-B-ion implantation, where amorphization initiates at the surface and then proceeds deeper into the material (typical of light ions). ${ }^{17}$ Thus, while $Q_{\text {equiv }}$ may be lowered for cluster-ion implantation, the qualitative evolution compared with single-ion implantation is basically the same.
Figure 2a-d displays WBDF-PTEM images of samples annealed at $800^{\circ} \mathrm{C}$ for $0.5 \mathrm{~h}$. In cases of $Q_{\text {equiv }}=0.1 \times 10^{15} \mathrm{~cm}^{-2}$ to $1.0 \times 10^{15} \mathrm{~cm}^{-2}$, the resulting samples were indistinguishable and only the $1.0 \times 10^{15} \mathrm{~cm}^{-2}$ case is presented for clarity, as shown in Fig. 2a. For this lower range of $Q_{\text {equiv }}$, no residual defects were observed, indicating a defect density $N_{\mathrm{D}}<2 \times 10^{7} \mathrm{~cm}^{-2}$ (TEM detection limit). In the case of $Q_{\text {equiv }}=2.0 \times 10^{15} \mathrm{~cm}^{-2}$, shown in Fig. $2 \mathrm{~b}$, more defects were observed, with $N_{\mathrm{D}}=$ $1.4 \times 10^{9} \mathrm{~cm}^{-2} \pm 0.6 \times 10^{9} \mathrm{~cm}^{-2}$. On increasing the dose to $Q_{\text {equiv }}=4.0 \times 10^{15} \mathrm{~cm}^{-2}$, shown in Fig. $2 \mathrm{c}, N_{\mathrm{D}}$ further increases to $3.6 \times 10^{9} \mathrm{~cm}^{-2} \pm$ $1.0 \times 10^{9} \mathrm{~cm}^{-2}$. Finally, for $Q_{\text {equiv }}=8.0 \times$ $10^{15} \mathrm{~cm}^{-2}$, individual defects were nearly indistinguishable, with $N_{\mathrm{D}} \gg 1.3 \times 10^{10} \mathrm{~cm}^{-2}$.

To better understand the nature and distribution of the defects, WBDF-XTEM was perform on annealed samples with $Q_{\text {equiv }}=2.0 \times 10^{15} \mathrm{~cm}^{-2}$ to $8.0 \times 10^{15} \mathrm{~cm}^{-2}$, as shown in Fig. 3a-c. In all cases, $\sim 3 \mathrm{~nm}$ of $\mathrm{SiO}_{2}$ was observed at the surface, presumably the result of slight thermal oxidation during annealing and atmospheric exposure. In the case of $Q_{\text {equiv }}=2.0 \times 10^{15} \mathrm{~cm}^{-2}$, shown in Fig. 3a, the sample appears defect-free, which is expected due to the low $N_{\mathrm{D}}$ observed in Fig. 2b. For $Q_{\text {equiv }}=4.0 \times 10^{15} \mathrm{~cm}^{-2}$, shown in Fig. 3b, isolated regions with stacking faults and microtwins were observed. With $Q_{\text {equiv }}=8.0 \times 10^{15} \mathrm{~cm}^{-2}$, shown in Fig. 3c, stacking faults and microtwins were observed throughout the whole of the sample from the surface to $\sim 40 \mathrm{~nm}$ into the sample (indicative of a polycrystalline microstructure). In all cases 


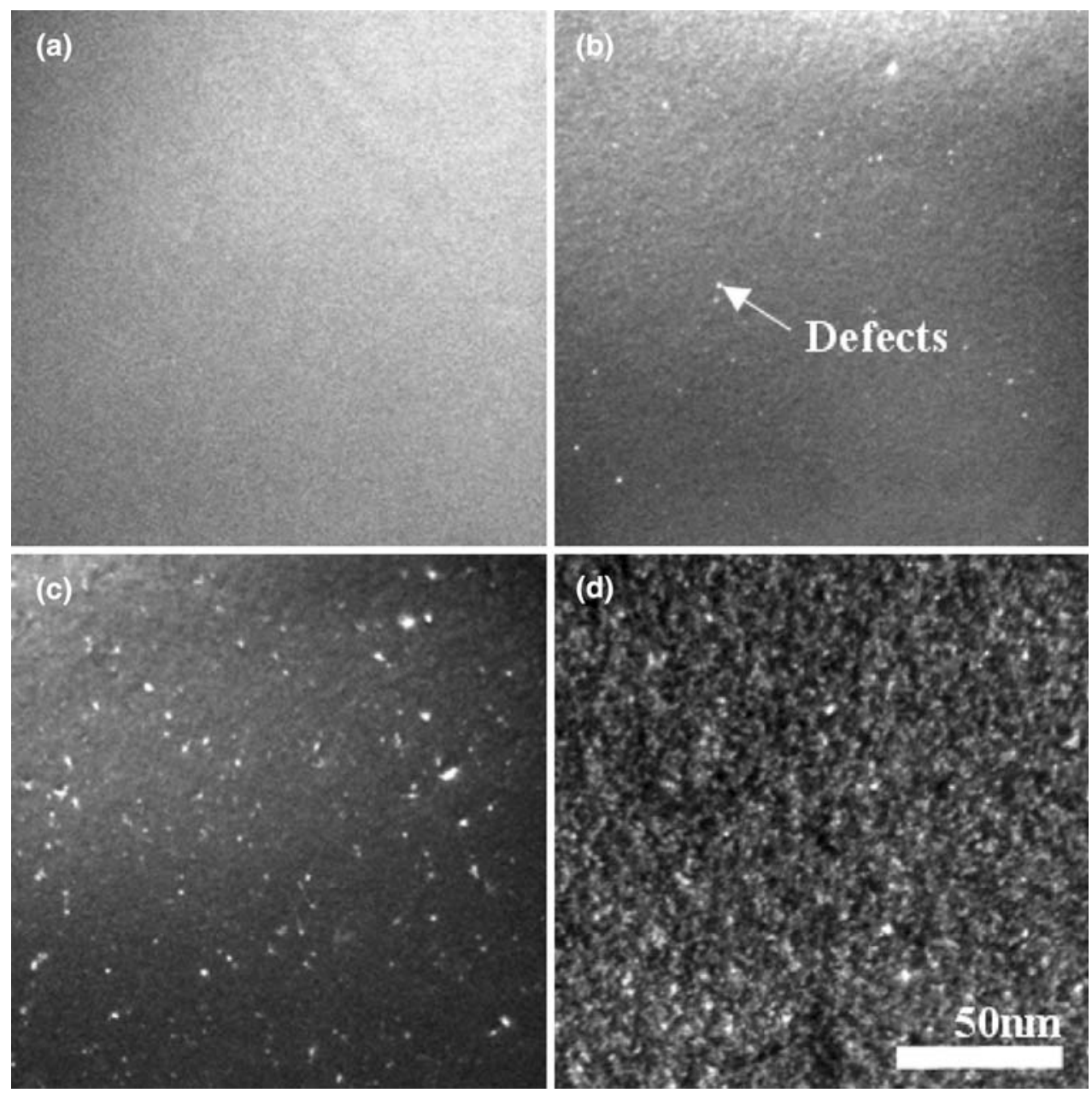

Fig. 2. WBDF-PTEM images of specimens implanted with $\mathrm{C}_{7} \mathrm{H}_{7}$ ions at a C-equivalent energy of $10 \mathrm{keV}$ with $\mathrm{C}$ doses of (a) $1.0 \times 10^{15} \mathrm{~cm}^{-2}$, (b) $2.0 \times 10^{15} \mathrm{~cm}^{-2}$, (c) $4.0 \times 10^{15} \mathrm{~cm}^{-2}$, and (d) $8.0 \times 10^{15} \mathrm{~cm}^{-2}$ after annealing at $800^{\circ} \mathrm{C}$ for $0.5 \mathrm{~h}$.
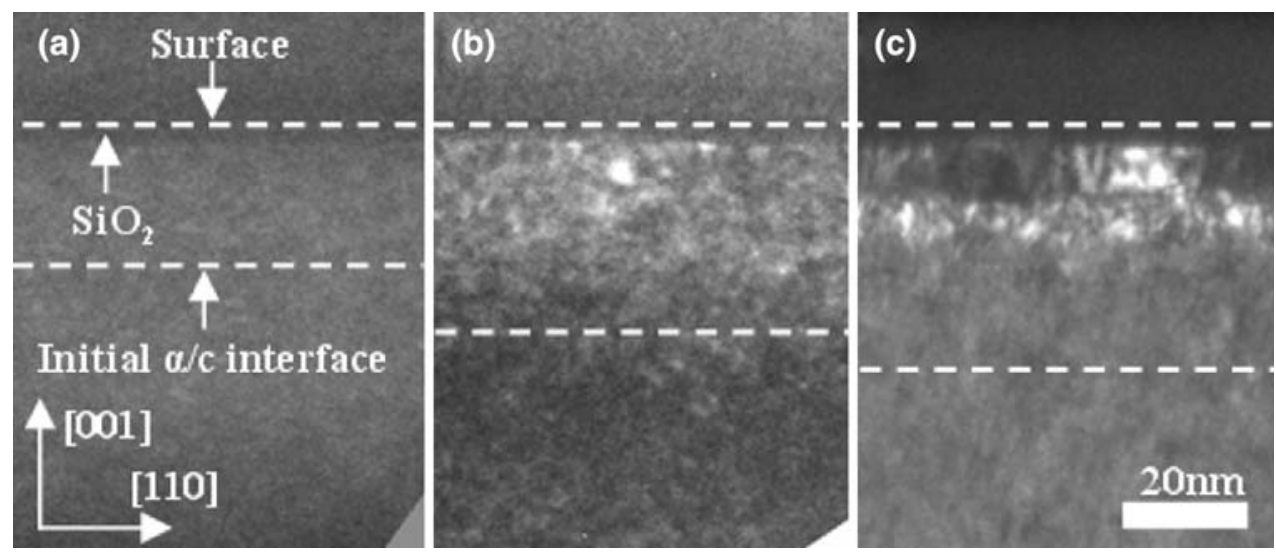

Fig. 3. WBDF-XTEM images of specimens implanted with $\mathrm{C}_{7} \mathrm{H}_{7}$ ions at a C-equivalent energy of $10 \mathrm{keV}$ with $\mathrm{C}$ doses of (a) $2.0 \times 10^{15} \mathrm{~cm}^{-2}$ (b) $4.0 \times 10^{15} \mathrm{~cm}^{-2}$, and (c) $8.0 \times 10^{15} \mathrm{~cm}^{-2}$ after annealing at $800^{\circ} \mathrm{C}$ for $0.5 \mathrm{~h}$. The initial $\alpha /$ crystalline $(\alpha / \mathrm{c})$ interface in each image is schematically noted.

where amorphization was achieved, no defects were observed near the initial $\alpha /$ crystalline interface following annealing.
From Fig. 3, it appears that the SPEG process breaks down as the $\mathrm{C}$ content increases, first by forming isolated defects and then by polycrystalline 
growth. To determine the nature of this process, SAED along the $B=[001]$ zone axis was performed on the annealed sample with $Q_{\text {equiv }}=8.0 \times$ $10^{15} \mathrm{~cm}^{-2}$ (data not shown). In addition to the spots from the Si substrate, three weak rings from the polycrystalline layer were present, with planar spacings of $\sim 3.2 \mathrm{~A}, 2.0 \mathrm{~A}$, and $1.6 \mathrm{~A}$ for the first, second, and third rings, respectively. In fact, these planar spacings are very similar to the known $\{111\}$, $\{022\}$, and $\{113\}$ planar spacings of $\mathrm{Si}$ and can therefore not be attributed to a $\mathrm{Si}-\mathrm{C}$ phase. Thus, the polycrystalline layer resulting from the SPEG breakdown at $Q_{\text {equiv }}=8.0 \times 10^{15} \mathrm{~cm}^{-2}$ is polycrystalline Si.

It is well known that stressed films undergo growth-mode transitions and morphological instability depending on the level of stress during growth. ${ }^{18-24}$ From Fig. 3c, it appears that SPEG completely breaks down at a depth of $\sim 40 \mathrm{~nm}$, which is near the maximum implanted $\mathrm{C}$ concentration $\left(C_{\text {max }}\right)$ for $E_{\text {equiv }}=10 \mathrm{keV}$ as predicted by simulations. ${ }^{25}$ However, in the case of $Q_{\text {equiv }}=1.0 \times$ $10^{15} \mathrm{~cm}^{-2}$, no defects were observed and it is reasonable to assume that any stress generated from $\mathrm{C}$ incorporation was fully maintained for this equivalent dose. In this case, $C_{\max } \approx 2.0 \times 10^{20} \mathrm{~cm}^{-3}$, which is equivalent to a C mole fraction of $X \approx 0.004$. Using a Vegard's law approximation for two materials with the same crystal structure, the lattice parameter of a $\mathrm{Si}-\mathrm{C}$ alloy is given by $a=a_{\mathrm{Si}}(1-X)+a_{\mathrm{C}} X$, where $a_{\mathrm{Si}}=0.543 \mathrm{~nm}$ is the lattice parameter of $\mathrm{Si}$ and $a_{\mathrm{C}}=0.357 \mathrm{~nm}$ is the lattice parameter of $\mathrm{C}$ in diamond-cubic form. ${ }^{26}$ Thus, with $X=0.004, a=0.542 \mathrm{~nm}$. In the absence of any strain relaxation, which was confirmed for $Q_{\text {equiv }}=1.0 \times 10^{15} \mathrm{~cm}^{-2}$ using x-ray $\omega-2 \theta$ rocking curve analysis (data not shown), the in-plane strain is given by $\varepsilon_{11}=a_{\mathrm{Si}} / a-1=1.4 \times 10^{-3}$. The out-ofplane strain is then given by $\varepsilon_{33}=-2 C_{1122} / C_{1111}$, where $C_{1122}$ and $C_{1111}$ are the transverse and normal stiffness coefficients. ${ }^{27}$ Assuming the elastic properties of the alloy are the same as those of pure $\mathrm{Si}$ (reasonable for the dilute $\mathrm{C}$ concentrations used), $\varepsilon_{33}=-1.1 \times 10^{-3}$ which was also confirmed by $\mathrm{x}$-ray $\omega-2 \theta$ rocking curve analysis (data not shown). The alloy layer is thus in a state of in-plane biaxial tensile stress, which leads to the conclusion that the majority of the implanted $\mathrm{C}$ has become substitutional. Therefore, the in-plane stress is given by $\sigma_{11}=2 C_{1111_{11}} \varepsilon_{11}+C_{1122} \varepsilon_{33} \approx 0.4 \mathrm{GPa}$ for $Q_{\text {equiv }}=$ $1.0 \times 10^{15} \mathrm{~cm}^{-2}$. In the case of $Q_{\text {equiv }}=2.0 \times$ $10^{15} \mathrm{~cm}^{-2}\left(C_{\max } \approx 4.0 \times 10^{20} \mathrm{~cm}^{-3}\right)$, SPEG was defective, as evidenced by Fig. $2 \mathrm{~b}$, and some stress relaxation has therefore likely occurred. Thus, $2.0 \times 10^{20}<C_{\max }<4.0 \times 10^{20} \mathrm{~cm}^{-3}$ is the limit for the amount of $\mathrm{C}$ that can be substitutionally incorporated during SPEG such that stress relaxation and defect formation are avoided.

By way of comparison, a prior study ${ }^{28}$ of C-influenced SPEG using single-ion implantation into preamorphized Si reported that polycrystalline growth (though not defective growth) was avoided for $X<0.019$, which matches well with this study, where polycrystalline growth was avoided for $X<0.016$. Thus, C-cluster-ion implantation is advantageous over single-ion implantation in that no pre-amorphization step is necessary prior to effecting SPEG for C incorporation.

Finally, it is important to note that fairly large doses of $\mathrm{H}^{+}$were also implanted into all samples, owing to the inherent nature of the cluster ions used for this work. This is necessary to consider since it is well known that annealing of $\mathrm{H}^{+}$-implanted Si results in the formation of bubbles and other defects. ${ }^{29,30}$ However, the dose regimes necessary for this to occur are well outside those used in the presented work so it is reasonable to conclude that the presence of $\mathrm{H}$ during annealing did not appreciably influence the SPEG process or the generation of defects.

\section{CONCLUSIONS}

The evolution of amorphization and SPEG of C-cluster-ion implanted Si were studied. Results suggest that the effective cluster-ion dose for amorphization is much less than the corresponding single-ion dose. Analysis of $\mathrm{C}$ incorporation during SPEG of amorphized samples suggested defect-free growth for a maximum substitutional $\mathrm{C}$ content of $2.0 \times 10^{20}<C_{\max }<4.0 \times 10^{20} \mathrm{~cm}^{-3}$, with defective SPEG and polycrystalline growth at higher concentrations. The use of C-cluster-ion implantation is also advantageous over single-C-ion implantation since no pre-amorphization step is necessary for $\mathrm{C}$ incorporation in the former case.

\section{ACKNOWLEDGEMENTS}

The authors acknowledge the Semiconductor Research Corporation for funding this research. The Major Analytical Instrumentation Center at the University of Florida is acknowledged for use of the focused ion beam, x-ray diffraction, and transmission electron microscope facilities.

\section{REFERENCES}

1. International Technology Roadmap for Semiconductors (2008), pp. 33.

2. K. Goto, J. Matsuo, Y. Tada, T. Sugii, and I. Yamada, IEEE Trans. Electron. Dev. 46, 683 (1999). doi:10.1109/16.753701.

3. K.S. Jones, S. Prussin, and E.R. Weber, Appl. Phys. A 45, 1 (1988). doi:10.1007/BF00618760.

4. X. Lu, L. Shao, X. Wang, J. Liu, W.-K. Chu, J. Bennet, L. Larson, and P. Ling, J. Vac. Sci. Tech. B 20, 992 (2002). doi:10.1116/1.1479361.

5. Y. Kawasaki, T. Kuroi, T. Yamashita, K. Horita, T. Hayashi, M. Ishibashi, M. Togawa, Y. Ohno, M. Yoneda, T. Horsky, D. Jacobson, and W. Krull, Nucl. Instrum. Methods Phys. Res. B 237, 25 (2005). doi:10.1016/j.nimb.2005.04.073.

6. D. Takeuchi, N. Shimada, J. Matsuo, and I. Yamada, Nucl. Instrum. Methods Phys. Res. B 121, 345 (1997). doi: 10.1016/S0168-583X(96)00451-X.

7. K. Goto, J. Matsuo, T. Sugii, H. Minakata, I. Yamada, and T. Hisatsugu, IEDM Tech. Dig. 435 (1996). doi:10.1109/ IEDM.1996.553620. 
8. Y. Hada, Physica B 340-342, 1036 (2003). doi:10.1016/ j.physb.2003.09.193.

9. I. Yamada, J. Matsuo, N. Toyoda, and A. Kirkpatrick, Mater. Sci. Eng. R. Rep. 34, 231 (2001).

10. T. Seki, J. Matsuo, G.H. Takaoka, and I. Yamada, Nucl. Instrum. Methods Phys. Res. B 206, 902 (1997). doi: 10.1016/S0168-583X(03)00896-6.

11. P.A. Stolk, D.J. Eaglesham, H.J. Gossmann, and J.M. Poate, Appl. Phys. Lett. 66, 1370 (1995). doi:10.1063/1.113204.

12. H. Rucker, B. Heinemann, W. Ropke, R. Kurps, D. Kruger, G. Lippert, and H.J. Osten, Appl. Phys. Lett. 73, 1682 (1998). doi:10.1063/1.122244.

13. S. Nishikawa, A. Tanaka, and T. Yamaji, Appl. Phys. Lett. 60, 2270 (1992). doi:10.1063/1.107051.

14. P.R. Chidambaram, C. Bowen, S. Chakravarthi, C. Machala, and R. Wise, IEEE Trans. Electron. Dev. 53, 944 (2006). doi: 10.1109/TED.2006.872912.

15. M.V. Fischetti and S.E. Laux, J. Appl. Phys. 80, 2234 (1996). doi:10.1063/1.363052.

16. M.M. Reiger and P. Vogl, Phys. Rev. B 48, 14276 (1993). doi: 10.1103/PhysRevB.48.14276.

17. K.S. Jones, D.K. Sadana, S. Prussin, J. Washburn, E.R. Weber, and W.J. Hamilton, J. Appl. Phys. 63, 1414 (1988). doi:10.1063/1.341122.

18. F.C. Frank and J.H. van der Merwe, Proc. R. Soc. London A 198, 205 (1949). doi:10.1098/rspa.1949.0095.
19. M. Volmer and A. Weber, Z. Phys. Chem. 119, 277 (1926).

20. I.N. Stranski and L. Von Krastanow, Akad. Wiss. Lit. Mainz Math.-Natur. K1. IIb 146, 797 (1939).

21. N.G. Rudawski, K.S. Jones, and R. Gwilliam, Appl. Phys. Lett. 91, 172103 (2007). doi:10.1063/1.2801518.

22. N.G. Rudawski, K.S. Jones, and R. Gwilliam, Phys. Rev. Lett. 100, 165501 (2008). doi:10.1103/PhysRevLett.100. 165501.

23. N.G. Rudawski, K.S. Jones, and R. Gwilliam, Mater. Sci. Eng. R. Rep. 61, 40 (2008).

24. N.G. Rudawski, K.S. Jones, and R. Gwilliam, Appl. Phys. Lett. 92, 232110 (2008). doi:10.1063/1.2945291.

25. J.F. Ziegler, Nucl. Instrum. Methods Phys. Res. B 219-220, 1027 (2003). doi:10.1016/j.nimb.2004.01.208

26. L. Vegard, Z. Phys. 5, 17 (1921). doi:10.1007/BF01349680.

27. J.J. Wortman and R.A. Evans, J. Appl. Phys. 36, 153 (1965). doi:10.1063/1.1713863.

28. J.W. Strane, S.R. Lee, H.J. Stein, S.T. Picraux, J.K. Watanabe, and J.W. Mayer, J. Appl. Phys. 79, 637 (1996). doi:10.1063/1.360806.

29. G.F. Cerofolini, F. Corni, S. Frabboni, C. Nobili, G. Ottaviani, and R. Tonni, Mater. Sci. Eng. R. Rep. 27, 1 (2000).

30. X. Lu, N.W. Cheung, M.D. Strathman, P.K. Chu, and B. Doyle, Appl. Phys. Lett. 71, 1804 (1997). doi:10.1063/1. 119404. 